\title{
ECTOPIC MENINGIOMA OF THE MANDIBLE: A RARE SITE OF PRESENTATION FOR A COMMON TUMOUR
}

\author{
Preethi Murthy1, Murthy Molaiyappan²
}

${ }^{1}$ Assistant Professor, Department of Pathology, Karpagam Faculty of Medical Sciences and Research, Coimbatore. 2 Professor, Department of Pathology, Karpagam Faculty of Medical Sciences and Research, Coimbatore.

\begin{abstract}
Meningiomas are leptomeningeal tumours that commonly occur intracranially. The other favoured sites include intraspinal and orbital regions. According to the WHO, case reports of meningioma occurrence have been published in almost all organs, albeit rarely.(1) These are known as ectopic meningiomas. To date only 5 cases of meningioma of mandible have been reported in the English literature, one of those having been reported in a 10-year-old child with basal cell nevus syndrome. $(2,3,4,5)$ We are hereby presenting the case of a 41-year-old female patient with a long-standing swelling in the right submandibular region. On imaging her mandible showed a depressed eroded area and the salivary gland was visualized separately. The tumour was excised and reported histopathologically as ectopic meningioma of the mandible. The diagnosis was later confirmed with immunohistochemistry.
\end{abstract}

\section{KEYWORDS}

Meningioma, Ectopic, Mandible.

HOW TO CITE THIS ARTICLE: Murthy P, Molaiyappan M. Ectopic meningioma of the mandible: a rare site of presentation for a common tumour. J. Evolution Med. Dent. Sci. 2016;5(51):3350-3352, DOI: 10.14260/jemds/2016/775

\section{INTRODUCTION}

Meningioma is a common leptomeningeal tumour usually restricted to the intracranial, intraspinal and orbital regions. Rarely these tumours can occur at other sites.(1) Such meningiomas are termed as ectopic meningiomas. Mandible is an extremely rare site of presentation for these tumours. To date, only five such cases have been published in the English literature.(2-5) We present one such case of ectopic meningioma occurring in the mandible of a 40-year-old female patient. We have supported our histopathological observations with immunohistochemical studies, which showed positive staining for vimentin and EMA in the tumour. The Ki-67 index was around 2\%, insufficient for a diagnosis of atypical (Grade II) meningioma.(1)

\section{CASE REPORT}

A 41-year-old female patient presented with a history of an insidious onset, gradually progressive swelling of 10 years' duration located in the right submandibular region. Imaging studies showed that the tumour was not connected to the submandibular salivary gland. The tumour was attached to the mandible. At the site of attachment, the mandible showed a depressed eroded region.

The surgeon did an excision biopsy of the tumour and we received a greyish-white soft mass measuring $2.5 \times 1.5 \times 1.5$ centimetres in size. It had a greyish white fibrous appearing cut surface.

Financial or Other, Competing Interest: None.

Submission 01-05-2016, Peer Review 04-06-2016,

Acceptance 09-06-2016, Published 27-06-2016.

Corresponding Author:

Dr. Preethi Murthy,

\#30, CAT Nagar,

Kannapiran Mill Road,

Sowripalayam,

Coimbatore-641028.

E-mail: nandhu4kutti@yahoo.com

DOI: $10.14260 /$ jemds/2016/775

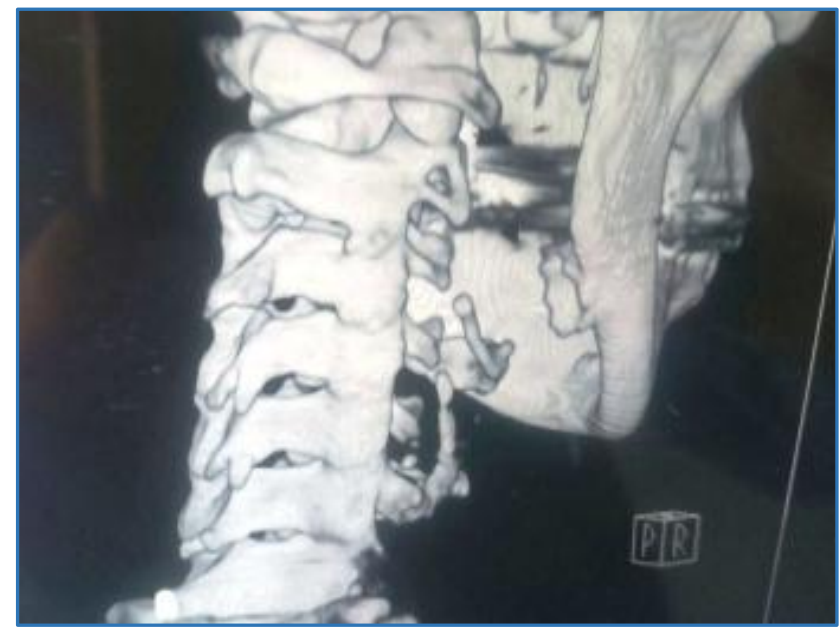

Fig. 1: CT of Mandible showing Focus of Erosion

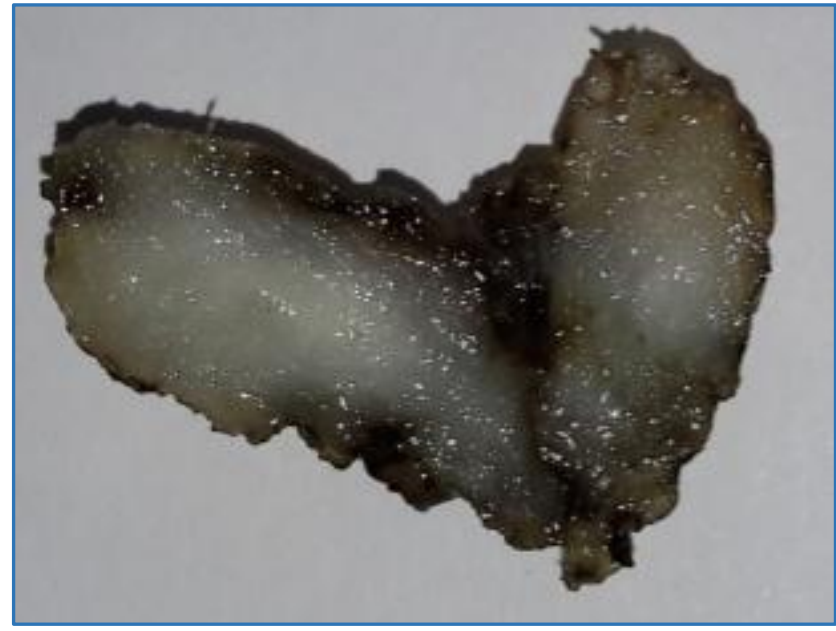

Fig. 2: Cross-Section of Tumour Mass

Histologically, the tumour was composed of epithelioid cells in syncytial sheets as well as spindled cells arranged in whorls and short fascicles. Nuclei were round to ovoid with open chromatin. There were not any features suggestive of atypical or anaplastic meningioma such as nuclear 
pleomorphism, increased mitosis, atypical mitosis or necrosis. Morphologically, the tumour was reported as extracranial meningioma. It was confirmed by a positive immunostaining for vimentin and EMA by most of the tumour cells. S100 showed positive reaction focally.

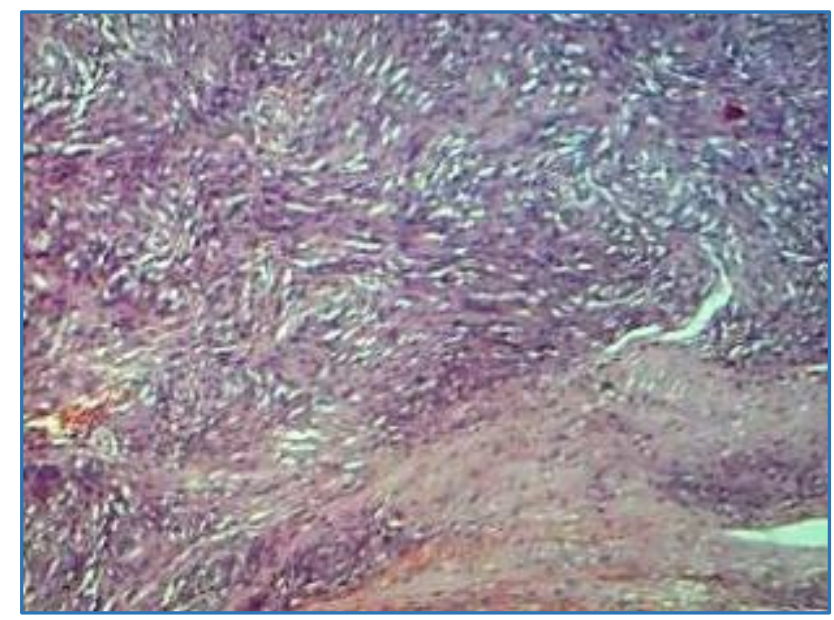

Fig. 3: Spindle Cells in Fascicles. H\&E; $x 100$

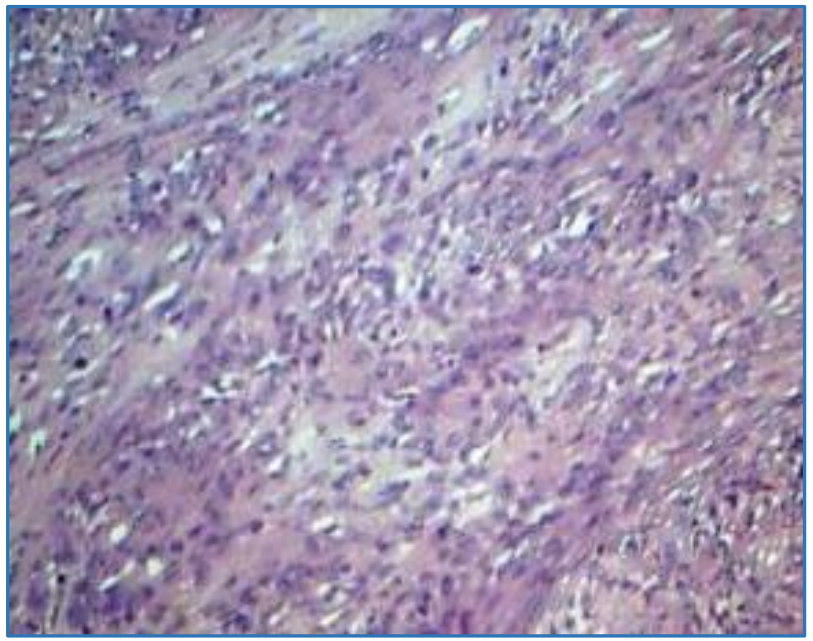

Fig. 4: Epithelioid Cells in Whorls. H\&E; $x 100$

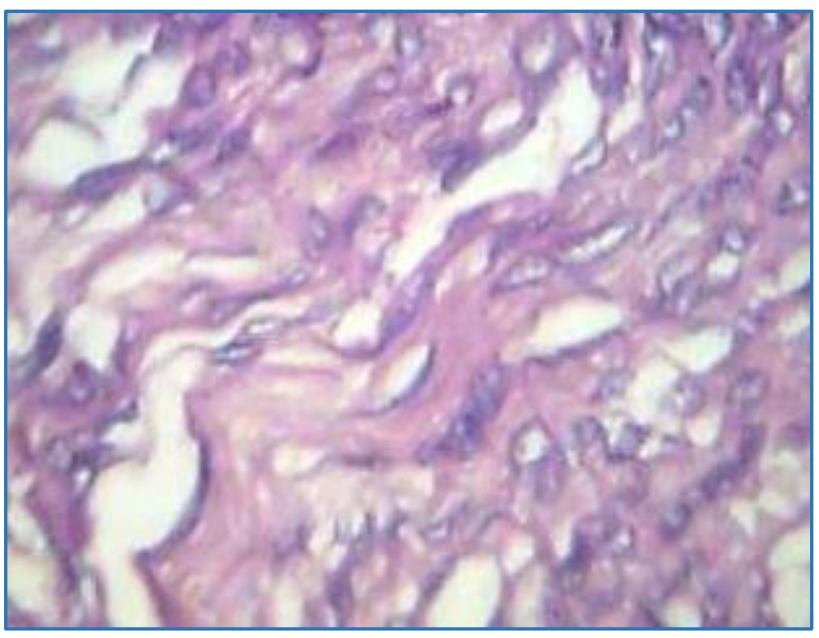

Fig. 5: Elongated Plump Nuclei with Open Chromatin. H\&E; $x 450$

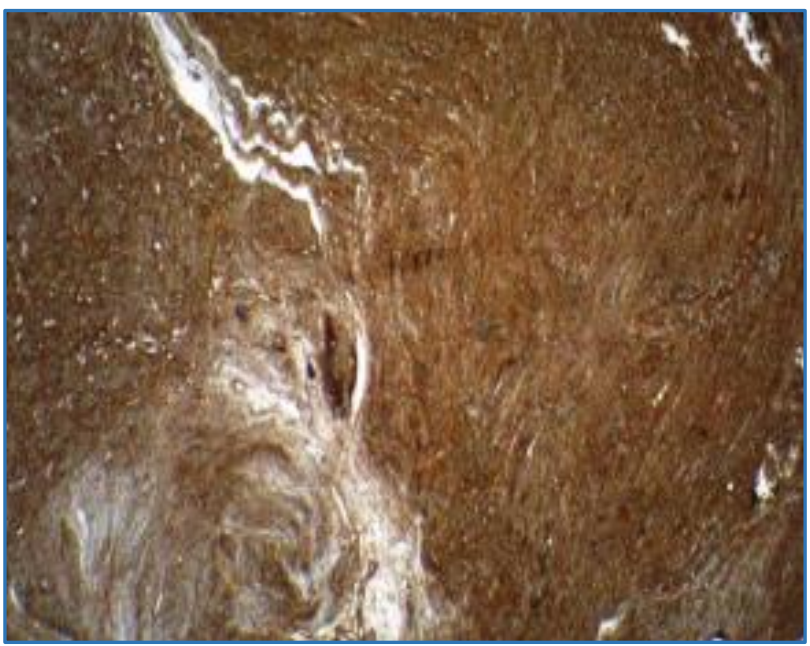

Fig. 6: Vimentin Positivity in Almost all Tumour Cells

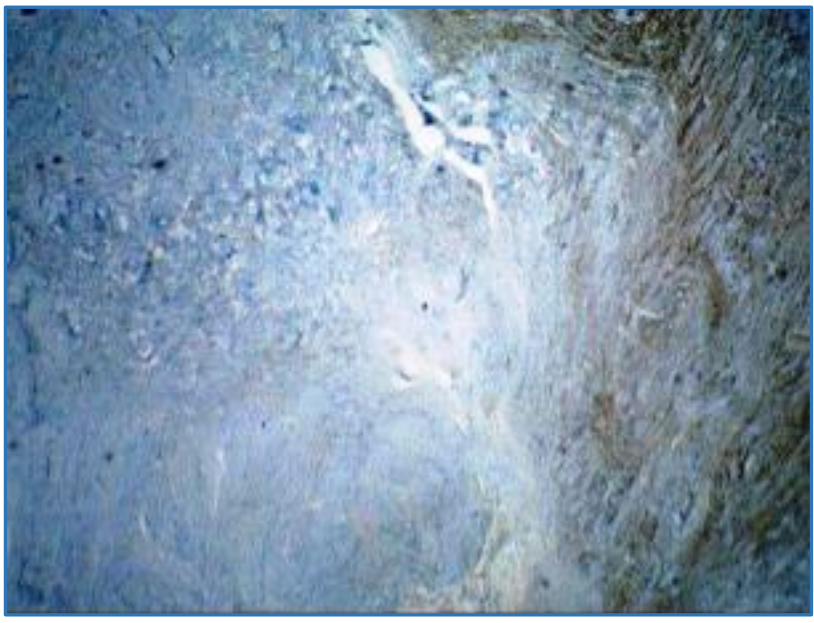

Fig. 7: EMA Positivity in Most of the Tumour Cells

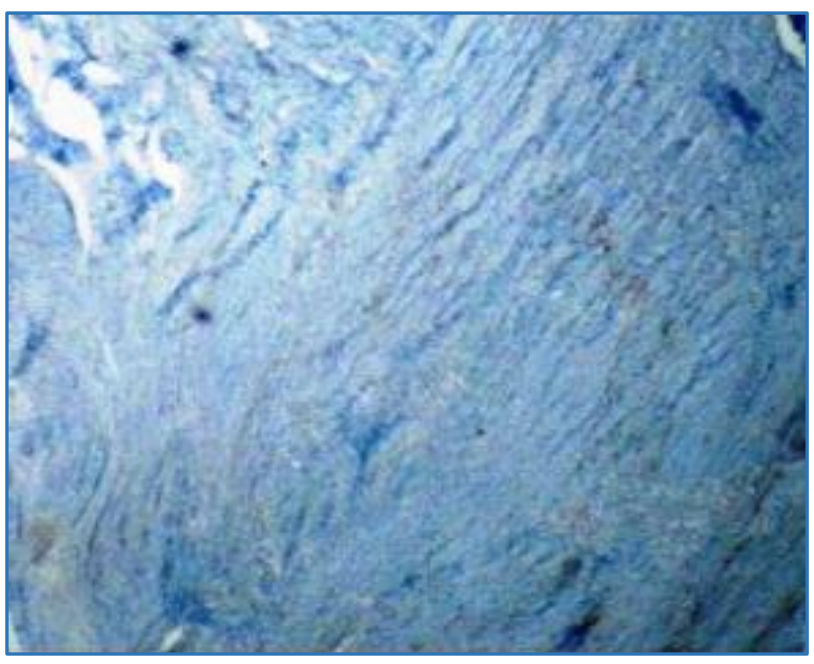

Fig. 8: S 100 Positivity in Very Few Tumour Cells

\section{DISCUSSION}

Meningiomas are common in intracranial, intraspinal and orbital regions where leptomeninges cover the brain, spinal cord and the orbital nerve, respectively.(1) Ectopic meningiomas are rare. The sites where ectopic meningiomas have been reported with a higher frequency include those where neural tube closure problems during intrauterine life could have led to the development of meningeal rests. These are classified as type 1 ectopic meningiomas. 
These sites are skin and soft tissue of the scalp and along the vertebral axis. Type 2 sites include regions near sense organs and along cranial and spinal nerve pathways. Ectopic meningiomas are extremely rare where meningeal rests are non-existent, such as the case in mandibular meningioma.(6) Ackerman proposes that the cell of origin at such sites could be perineurial cells.(7)

To date only four cases of meningioma of mandible have been reported in the English literature. The first ever case was reported in 1992, in the Journal, Cancer. The authors supported their diagnosis with immunohistochemical as well as ultrastructural studies.(2) The next report came out in 2001 of 2 female patients presenting with mandibular lesions reported as meningiomas by histopathology and immunohistochemical studies.(3) The last case reported in 2007 was in a 62-year-old man. This was the first ever radiological description of a Mandibular meningioma in published literature.(4) One other case has been reported in a 10-year-old boy with basal cell nevus syndrome.(5)

The main differential diagnosis at this site is perineurioma. The cells in perineurioma are longer and thinner with elongated spindled nuclei as opposed to the plump nuclei of meningioma cells. The cells in perineurioma tend to form perivascular whorls and in intraneural cases they form pseudo-onion bulbs around residual nerve fibres which stain positive for S100.(8)

At other sites such as the nasopharynx, an ectopic meningioma may mimic angiofibroma or olfactory neuroblastoma clinically.

Histology and immunohistochemistry can easily differentiate these tumours from meningioma. The psammomatous variant of meningioma at ectopic sites near bone will need to be differentiated from aggressive psammomatoid ossifying fibroma. These tumours occur at a younger age and show the presence of osteoclasts and osteoblasts.(8)

\section{REFERENCES}

1. Louis DN, Ohgaki H, Wiestler OD, et al. The 2007 WHO classification of tumours of the central nervous system. Acta Neuropathol 2007;114(2):97-109.

2. Landini G, Kitano M. Meningioma of the mandible. Cancer 1992;69(12):2917-20.

3. Jones AC, Freedman PD. Primary extracranial meningioma of the mandible: a report of 2 cases and a review of literature. Oral Surg Oral Med Oral Pathol Oral Radiol Endod 2001;91(3):338-41.

4. Mussak EN, Holodny AI, Karimi SK. Meningioma of the mandible: imaging with CT. Am J Neuroradiol 2007;28:1157-9.

5. Kubota Y, Yamashiro T, Kobayashi I, et al. Primary meningioma of the mandible. Oral Oncology Extra 2005;41(2):18-21.

6. Goldblum JR, Polpe AL, Sharon WW. Ensinger and Weiss's soft tissue tumours. $6^{\text {th }}$ ed. Elsevier 2014.

7. Rosai J. Rosai and Ackerman's surgical pathology. 10 $10^{\text {th }} \mathrm{ed}$. Elsevier 2012.

8. Fisher C, Mentzel T, Montgomery EA, et al. Diagnostic pathology. Soft tissue tumours. 1st ed. Amirsys Inc 2011. 